\title{
Research
}

\section{Caring for the carers: the characteristics of district nursing support for family carers}

Kate Gerrish Centre for Health and Social Care Research, Sheffield Hallam University, Sheffield, UK

\begin{abstract}
Aim: This paper presents findings from an ethnographic study that examined how qualified district nurses' conceptualized their role in relation to family carers and how they performed this aspect of their role. Methods: A participant observational study involving fieldwork and in-depth interviews with six district nursing teams was undertaken over a 12-month period. Interview transcripts and fieldnotes were analysed by drawing upon the principles of dimensional analysis. Findings: District nurses acted on the assumption that family carers would, by choice or default, provide care. Family carer support was conceptualized as a means of promoting self-care and the patient's independence from nursing services. The rationale for providing family carer support was based largely on service capacity rather than on carer needs and preferences. Six characteristics of district nursing support for carers were identified: enabling, supporting, mediating, care substitution, crisis prevention and crisis intervention. Family carers were not recipients of district nursing support in their own right but were dependent upon the cared-for person receiving nursing care. This in turn was conditional upon others (general practitioners and hospitals) making appropriate patient referrals. Family carer support was also conditional upon effective communication and family carer receptiveness. Conclusion: As the scope of home-based nursing continues to increase, district nurses need to take a more active stance in providing family carer support and adopt a family rather than patientfocused approach in order that family carers might be supported more effectively.
\end{abstract}

Key words: district nursing; ethnography; family carer; support

Received: May 2006; accepted: November 2007

\section{Introduction}

District nursing is concerned with providing care in the home to people with acute and chronic health problems. The current shifting boundary between secondary and primary health care has led to the relocation of complex nursing care from hospital to primary care. This transfer places greater emphasis on the role of family carers. It also blurs the

\footnotetext{
Address for correspondence: Kate Gerrish, Centre for Health and Social Care Research, Sheffield Hallam University, 32 Collegiate Crescent, Sheffield S10 2BP, UK. Email: k.gerrish@shu.ac.uk
}

boundaries between formal and informal care when family carers may be involved in undertaking what have hitherto been regarded as nursing procedures (Kirk and Glendinning, 1998; Pickard et al., 2000; 2003; Pickard and Glendinning, 2002). This in turn has important implications for the respective roles of nurses and family carers, in particular, the role of district nurses in supporting family carers.

Many Western governments have acknowledged the contribution of family carers by introducing legislation concerning how formal services can best support their needs (Wiles, 2003). However, policy guidance on carer support in other European countries and Australia differs in that it reflects the 
historical assumptions, values and structures that underpin the particular welfare systems and support in which they are embedded (Glendinning, 2003; Hanson et al., 2006). Moreover, the focus of policies on carers is somewhat confusing in that it is often unclear as to whether carers are regarded as needing support in their own right or as a resource for older people. Thus, in many instances there is little acknowledgement that carers may have needs that are separate from and in possible conflict with those of the person receiving care (Walker and Dewar, 2001; Glendinning, 2003).

In the UK, the Carers (Recognition and Services) Act (1995) was intended to give formal recognition to the rights and circumstances of family carers. Realization that the Act and related legislation was having limited effect led the government to launch the Carers National Strategy (Department of Health, 1999), an initiative intended to empower carers to take greater control of their lives and promote a change of culture amongst service providers so that carers were both recognized and respected for their contribution.

Given the legislation, carers might reasonably expect that their role is identified by primary care staff, their needs as a carer are assessed and they receive appropriate information and support to fulfil this role. However, although the research literature on family carers highlights the essential contribution they make to sustaining care in the community it also identifies the considerable burden many experience as caregivers (Nolan and Grant, 1989; Twigg et al., 1990; Parker and Lawton, 1994; Twigg and Atkin, 1994; Katbamna et al., 2004) and a general failure of statutory agencies to meet their needs (Cozens, 2002; Keeley and Clarke, 2003a). Moreover, a major review of support for family carers in the UK concluded that the situation remains unsatisfactory with the aspirations of carers not being realized in practice (Audit Commission, 2004).

Although district nurses rely heavily on family carers' contributions and acknowledge the need to provide carer support (McGarry and Arthur, 2001), they may have not been sufficiently supportive. Carers needs for information and education, psychological support, practical assistance with caring, access to resources and flexibility in service provision are frequently not met (Cameron et al., 1988; Henwood, 1998; Katamba and Bhakta, 1998; Luker et al., 2003; Arksey and Hirst, 2005).
Both patients and family carers perceive that district nurses have an important contribution to make in supporting family carers (McGarry and Arthur, 2001), yet comparatively few district nurses are proactive in fulfilling this role (Simon and Kendrick, 2001). Rather than anticipating carer needs in advance, they respond to problems as they arise. Lack of time, resources and training to provide support mitigate against effective carer support (Simon and Kendrick, 2001). Whereas Ong (1990) identified that family carers expected nurses to view them as full partners in care, conflict arises when nurses fail to recognize family carer expertise (Ward-Griffin and McKeever, 2000).

Nurses' responses to carers are also informed by how they perceive the carer's contribution. Twigg and Atkin's (1994) typology of caring portrays the complex and varied ways in which professionals engage with carers: carers may be seen as a resource to provide the bulk of support; as coworkers working alongside professionals; and as co-clients in need of support in their own right. A recent reassessment of this typology by Manthorpe et al. (2003) identifies how primary care professionals see carers primarily as a resource and co-workers but showed limited awareness of carers' responses and attitudes to caring.

It has also been suggested that the professional ideology of individualized care that underpins nursing policy and practice can mitigate against consideration of the family context in which the patient is located with the result that family carer needs are not prioritized (Gerrish, 2000; Brereton and Nolan, 2002).

Whereas research studies have focused on carers' perspectives of the support provided by district nurses, there has been comparatively little consideration of family carer support from the perspective of district nurses themselves. The study reported in this paper seeks to redress this imbalance by shedding further light on the nature of district nursing support for family carers.

\section{The study}

An ethnographic study was undertaken to examine how district nurses interpreted the ideology of individualized care in their everyday practice. This paper considers one of the emerging themes

Primary Health Care Research \& Development 2008; 9: 14-24 
concerning how district nurses perceived their role in supporting family carers and the various manifestations that such support took. The ethnographic approach adopted drew upon the subtle realist perspective outlined by Hammersley and Atkinson (1995).

Participant observation of nursing practice was undertaken involving six district nursing teams who worked for an English primary care organization serving a city with an ethnically diverse population. Teams were attached to general practices. Purposive sampling was used to identify teams, which reflected the varied socio-economic and ethnic composition of patients on the district nursing caseloads. One team served a predominantly South Asian inner city practice population, another team served a primarily white British suburban practice population and the remaining four teams served ethically mixed populations across the city.

Each team comprised a qualified district nurse and between two and four other nurses or health care support workers. Three discrete episodes of fieldwork, each lasting between 6 and 12 weeks were undertaken over a 12 -month period with 2-3 days per week spent in the field.

In order to achieve a balance between observing different nurses and providing the opportunity to observe how nurses provided care to patients who remained on the caseload for a period of time, the time spent with teams varied. Two teams were followed through for all three episodes of fieldwork, two teams for two episodes and two teams for one episode (see Table 1). Ethical approval was granted by the Local NHS Research Ethics Committee.

A participant observer role was adopted whereby I worked alongside the nurses, observing their actions and interactions with patients and family carers. Where appropriate I assisted with care delivery, for example where two nurses were required for a particular procedure. This equated to a peripheral membership role (Adler and Adler, 1998) in which the researcher observes and interacts closely with group members to establish an insider's identity without fully participating in the activities consisting core membership. In-depth interviews $(n=12)$ were undertaken with the district nurses following each episode of fieldwork.

The main focus of observation was on the work of the senior district nurse in each team although other qualified nurses were observed. Health care support workers were observed insofar as they undertook joint visits with the qualified nurse whom I was accompanying. Detailed fieldnotes were recorded and interviews were tape-recorded and subsequently transcribed verbatim. Pseudonyms were used to preserve the anonymity of participants.

Preliminary data analysis began concurrently with data collection. Emerging issues from one period of fieldwork were explored in subsequent fieldwork, including seeking out confirmatory and divergent cases, to enable further refinement of the issues. A more detailed analysis was undertaken once fieldwork was completed. This drew upon the principles of dimensional analysis (Schatzman, 1991) in identifying the various dimensions that informed an understanding of how district nurses provided care. Fieldnotes and transcripts were initially scrutinized in detail to map all the component dimensions and their respective properties. A tiered system of codes was developed for each of the dimensions and their properties. Data were then coded and the relationships between the different dimensions and properties refined. Those that were central to an understanding of the research aims were subsequently organized into overarching themes. This paper examines one of those themes, namely how the district nurses conceptualized and practised family carer support.

Table 1 Number of weeks spent with each district nursing team

\begin{tabular}{|c|c|c|c|c|c|c|c|}
\hline \multirow[b]{2}{*}{ Fieldwork episode } & \multicolumn{6}{|c|}{ Number of weeks spent with teams A-F } & \multirow[b]{2}{*}{ Total } \\
\hline & A & B & $\mathrm{C}$ & $\mathrm{D}$ & $\mathrm{E}$ & $\mathrm{F}$ & \\
\hline First & 2 & 2 & 2 & & & & 6 \\
\hline Second & 2 & 2 & & 2 & 2 & & 8 \\
\hline Third & 4 & 2 & 2 & 2 & & 2 & 12 \\
\hline Total & 8 & 6 & 4 & 4 & 2 & 2 & 26 \\
\hline
\end{tabular}

Primary Health Care Research \& Development 2008; 9: 14-24 


\section{Findings}

\section{Rationale for family carer support}

Although the primary focus of nursing intervention was on addressing the needs of patients, the patient's family and significant others occupied a pivotal role as family carers. All district nurses perceived that they had a role in supporting family carers:

It's part of our philosophy, we don't just look after the patient, we also look after the carers. They're helping to maintain that person in the home environment and we need to support them to do this.

(DN Team 1)

The rationale for providing family carer support was based largely on service capacity rather than carer needs:

We rely on carer input; the system would collapse without their involvement. Neither health nor social services have the capacity to provide care to everyone who needs it.

(DN Team 5)

It was acknowledged that the fragile infrastructure supporting the patient could collapse if the family carer was no longer able to cope. Should this occur, it would affect not only the patient's normalization but also place an additional burden on health and social care agencies. Yet, despite district nurses asserting that they supported family carers, they only did so as part of the package of care they provided to patients on their caseload: family carers were not recipients of district nursing in their own right but were dependent on general practitioners (GPs) or hospital services referring the patient to the district nursing service.

\section{Assessing and responding to carer needs}

None of the district nurses were observed to undertake an initial formal assessment of family carer needs. However, the carer was often present at the initial patient assessment visit and whereas the emphasis was on identifying the patient's needs some discussion took place with the carer regarding his or her role. Insight into the needs of family carers was obtained through conversations undertaken during subsequent visits to patients.
It was acknowledged that providing care was a stressful experience for many family carers and district nurses frequently sought information on how carers were coping. These discussions were largely ad hoc and opportunistic although occasionally visits were planned with the specific intention of addressing the needs of family carers.

Several patients and family carers were from a minority ethnic background, the majority being South Asian. Whereas the literature draws attention to health care professionals' stereotypical assumptions that South Asian families 'care for their own' (Merrell et al., 2005), the nurses in this study did not appear to hold such views. They sought to support family carers irrespective of their ethnic background. However, family carer support was conditional upon effective communication and many South Asian family carers, especially older women, were unable to communicate in English. In such situations, the district nurses relied on the patient or other family members who could speak English to assist them in engaging in a dialogue with the main carer rather than using professional interpreting services. However, on occasions, there was no one who was able to interpret for the family carer and the district nurses had very limited interaction with these carers. This contrasted sharply with the interactions that they had with South Asian carers who spoke English. English-speaking carers, irrespective of their ethnic background, were observed frequently to initiate dialogue concerning the patient and their role in providing care. Thus, language barriers had a considerable impact on the extent to which district nurses were able to identify the needs of, and provide support to, family carers who were not conversant in English.

District nursing intervention to support family carers took various forms: enabling, supporting, mediating, care substitution, crisis prevention and crisis intervention. These are presented below. The extent to which these interventions were 'successful' from the district nurse's perspective depended not only on the nurse's actions but also on the receptivity of the family carer to such intervention:

We may suggest things to the carer that may help their situation but they may not buy into it. It's a two way process, we can provide support but in order for it to work carers need to be receptive to our input.

Primary Health Care Research \& Development 2008; 9: 14-24 
We need to know where they are coming from, listen to their concerns, try to meet their needs. Most of the time carers value our input but, at the end of the day, if they don't want it there's not much we can do.

\section{Enabling}

All district nurses were committed to a philosophy of practice that promoted patients' independence from nursing services. This was achieved through promoting self-care or in situations where patients were unable to care for themselves by enabling family carers to assume responsibility for care:

Our role is to help patients take responsibility for their own health. It's important to promote their independence and the ability to take care of themselves. ...... Where patients aren't able to be self-caring we look to support the carers take on this role.

(DN Team 2)

However, it was recognized that economic constraints meant that it was not feasible to provide nursing care to everyone who might desire it at a level they might wish. The limited and expensive nursing resource had to be used wisely and family carers could be taught to assume responsibility for certain aspects of care.

In promoting patients' independence from nursing services, district nurses taught family carers how to provide physical care. Often this related to personal care, such as assistance with bathing, but it also extended to technical aspects of nursing care, for example, renewing wound dressings. Nurses were not always able to transfer responsibility for care to the carer and on occasions it was shared. For example, the nurses visited an elderly lady with diabetes who, due to failing eyesight, could not give herself insulin injections. The nurses had taught her adult daughter to administer the insulin, and when she could not do so due to shift work, they stepped in. The district nurses also facilitated family carers' access to resources to enable them to care, such as equipment or by referring to other agencies to provide support.

\section{Supporting}

The district nurses' role involved supporting family carers in order to maximize the carer's

Primary Health Care Research \& Development 2008; 9: 14-24 input. They sought to provide 'support from the sidelines' and between visits family carers were responsible for initiating contact with the nurses should they have concerns:

We leave it to carers to contact us if they're worried about anything. They know when we plan to visit again, if anything crops up in the meantime, they can phone us. If we don't hear from them, we assume things are OK.

(DN Team 6)

Whereas some family carers contacted the nurses by telephone to discuss concerns, it did not mean that carers who did not initiate contact did not require support. On some planned visits to patients, family carers were experiencing difficulties as the following vignette indicates:

On a routine visit to give an injection to Mrs Cooper we found her husband very distressed. Since the nurses' previous visit Mrs Cooper had become disorientated and developed urinary incontinence. Her husband was anxious about her personal safety, he was feeling exhausted due to disturbed nights and his symptoms of chronic bronchitis were worsening to the extent that he found it difficult to fulfil household responsibilities and care for his wife.

(Team 4)

The district nurses also maintained a 'watching brief' on carers whereby they occasionally undertook domiciliary visits with the specific intention of ascertaining how the carer was coping.

\section{Mediating}

Family carer intervention also involved district nurses mediating between carers and patients. This was most likely when there was a difference of opinion between the family carer and the cared-for person:

John was referred to the district nurses following a course of chemotherapy and radiotherapy for cancer of the Eustachian tube. When we arrived, John was upstairs and while we waited for him to join us, his wife confided that she had been trying to persuade him to consider a referral to the Macmillan nursing services but John became argumentative whenever she mentioned it. 
'Could you have a word with him?' she asked, 'I think the Macmillan nurses could help us both'.

Later on Liz (district nurse) introduced the idea of the Macmillan services and acted as a go-between, encouraging John and his wife to express their views on the appropriateness or otherwise of a referral. After a prolonged discussion John agreed to a referral. Reflecting on the visit Liz observed: 'It is up to them to decide whether they want the referral. I think it could help them both but they need to agree together. My job is helping them to see each other's point of view.'

(Team 2)

\section{Carer substitution}

The district nurses generally avoided providing care that in their opinion could be undertaken by family carers. Their objective was to maximize carers' input. Nevertheless, in situations where family carers encountered difficulties, district nurses substituted for carers' input. This was most likely to occur where male carers were caring for female relatives, especially across generations, or when the situation was likely to resolve itself:

We wouldn't normally bath someone. If the carer can't manage, we refer them to homecare. But Joyce is finding it hard to cope at the moment. She's been unwell, and needs a helping hand. So we'll help out with washing and dressing Jack for a couple of weeks, until she's feeling better. If she needs help longterm, we'll need to refer to social services.

(DN Team 4)

Moreover, with terminally ill patients, district nurses relinquished their commitment to promoting independence from nursing services, and accepted the need for ongoing and, in many instances, increased involvement in direct care. However, district nurses were not always consistent in the amount of support provided with older carers and male carers more likely to receive carer substitution.

\section{Crisis prevention}

All district nurses perceived that they had a role to play in averting a crisis situation evolving whereby the carer was no longer able to provide care. In some instances, support was increased by taking on some of the family carer's responsibilities on a short-term basis or making referrals to other agencies. In other situations, they increased the number of visits undertaken with the explicit purpose of providing additional psychological support to family carers. The district nurses also helped carers anticipate a future when they might no longer be able to care:

'Jane has learning disabilities and is physically disabled. We visit regularly to provide catheter care. Her mother has dementia, her condition's deteriorated and she's been admitted to a nursing home. Jane is putting a lot of pressure on her father who's in his $80 \mathrm{~s}$ and is finding it difficult to care for her. We're trying to persuade him to consider respite care for his daughter. It would give him a break and start to prepare Jane for long term care when he can no longer cope.'

(DN Team 3)

\section{Crisis intervention}

Despite district nurses trying to prevent a crisis situation arising, there were occasions when family carers reached a point when they felt no longer able to continue. The nurses saw their role as intervening with a view to alleviating carer stress while at the same time taking account of the patient's needs. In many instances this involved referral to other services:

When I visited it was clear that Mrs Brown wasn't coping any longer. She was chronically tired, she'd not had a proper night's sleep for months. She was at her wits end. I stepped in straight away and arranged respite care.

(DN Team 5)

Despite attempts to alleviate family carer burden, it was sometimes just a matter of time before a crisis occurred. For example, an adult daughter found it increasingly difficult to cope with her elderly mother who had chronic respiratory disease. Despite the option of respite care, the daughter considered it her responsibility to provide care and declined offers of help. Reflecting on the situation one nurse commented:

The family is in control and we have to let them stay in control. There will be carer

Primary Health Care Research \& Development 2008; 9: 14-24 


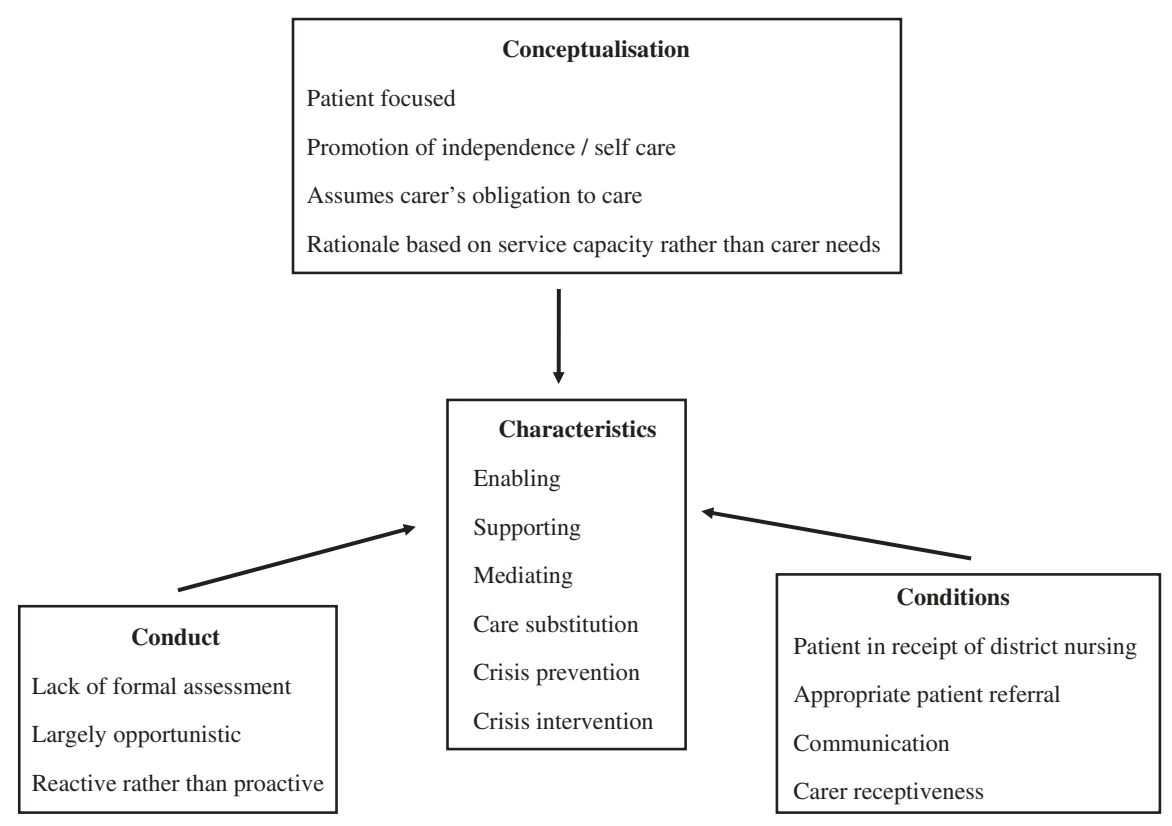

Figure 1 Dimensions of district nursing support for family carers

breakdown at some stage and we need to be there to offer support when it happens. In the meantime there's not much else we can do. It's hard to stand back and wait until a crisis arises but Jean (the patient's daughter) needs to make her own decisions.

(DN Team 2)

\section{Discussion}

The findings reported in this paper provide insight into district nurses' role in relation to family carers. These are depicted in Figure 1 which shows that the characteristics of district nursing support for family carers is influenced by certain conditions, the nurses' conceptualization of carer support and how district nurses conduct carer support.

There are similarities between the typology of caring developed by Twigg and Atkin (1994) and the findings of the current study. District nurses continue to see family carers as a resource and as co-workers whose contribution is essential to providing care in the community. Whereas Twigg and Atkin identified that carers' needs were often not identified and/or met, the findings from the

Primary Health Care Research \& Development 2008; 9: 14-24 current study indicate that district nurses do see carer support as an integral part of their role. This study has also shed light on the characteristics of the various ways in which district nurses work with carers. These developments may be a reflection of recent policy drives for health care professionals to provide family carer support. However, the study was undertaken in one primary care organization and therefore the findings may reflect local policy and practice. Moreover, the study focused solely on the nurses' perspective but as Pickard and Glendinning (2002) point out, professionals and carers may hold very different views about carer support. Further research, therefore, is required to verify these findings.

Much of the research examining family carer needs has focused on the carers of people with long-term illness or disability, and by implication has been orientated towards support provided by social services (Kirk and Glendinning, 1998). This study provides insight into the contribution that district nurses make to sustaining carers with both short- and long-term care-giving responsibilities. Such support, however, is dependent on certain conditions being fulfilled. 
First, the scope of district nursing support for family carers was confined to carers of patients who received district-nursing care. The separation of the responsibility for nursing and personal care has meant that some patients with long-term care needs who in the past might have been eligible for district nursing care now receive support from social services (Kirk and Glendinning, 1998). Family members who feel 'prepared' to care do so more effectively and experience lower levels of stress and greater satisfaction in their role (Nolan et al., 1996; Keeley and Clarke, 2003b). As this study has indicated, district nurses contribute towards equipping family carers with knowledge and skills to provide care. However, this role is largely responsive rather than proactive. Moreover, the boundaries defined by the district nurses' caseload may serve to exclude some family carers who could benefit from the modes of carer support identified in the current study, ie they care for people who do not receive district nursing intervention. The Audit Commission's (2004) review of support for carers of older people called for local multi-agency strategies to be established to address the needs of family carers. Although there are examples of successful cross-boundary working between health and social services, this is not well established in England and is fraught with sensitivities regarding resource allocation in relation to an already stretched budget.

Second, district nurses are reliant on GPs and hospitals to refer patients and thereby family carers to the service (Kirk and Glendinning, 1998; Gerrish, 2000). Yet other health care professionals often have limited understanding of the district nursing service. They may therefore fail to make appropriate patient referrals and by default family carers may not have access to district nursing support (Simon and Kendrick, 2001). The need for family carer support is often the greatest immediately following hospital discharge and whereas the Community Care (Delayed Discharges, etc.) Act 2000 requires that a formal assessment of carer need is undertaken prior to discharge if requested by the carer there is a need to consider providing short-term support to all family carers (Audit Commission, 2004).

Third, family carer support was dependent upon effective communication. The findings from this study support other research that identifies that district nurses make limited use of professional interpreters (Gerrish et al., 2004; Merrell et al., 2005) with the result that the needs of family carers who do not speak English are not taken into account. This is despite evidence of the need for carer support among people whose first language is not English (Katamba and Bhakta, 1998; Merrell et al., 2005).

Finally, the district nurses' ability to support family carers was dependent upon the carers themselves. Whereas carers were generally receptive to district nursing intervention there were some occasions, especially when nurses were seeking to avert a crisis situation arising, when their attempts to support family carers were thwarted. Such tensions may be a reflection of the complex dynamics of care-giving relationships in which reciprocity exists within the context of well-established and in many cases of life-long relationships (Arksey and Glendinning, 2007). Services and support may be rejected if they are not seen as consistent with carers' own wishes: a more effective way of aligning the support provided with the qualities desired by carers themselves is required (Nolan et al., 1996; Nolan et al., 2003).

Family carer support was conceptualized within the nurses' ideology of a patient-focused service and the current health policy directives promoting self-care. Family carers were instrumental in assisting nurses in their quest to promote patients' independence from nursing services. However, this approach subordinates the needs of family carers in preference to those of patients. Nolan et al. (1996) argue instead for a family-focused ideology of care in which the needs of family carers are considered with equal merit alongside those of patients. Yet the nurses in the current study only took account of carers' views within the context of providing care to patients on their caseload. Assessment of carer needs was subsumed within the patient assessment and was generally an opportunistic rather than a planned activity. Moreover the approach to addressing carer needs focused on the burden of caring in terms of preventing and/or alleviating a crisis and failed to recognize the potential satisfactions of caring. Nolan et al. (2003) have argued for models of carer support in which carers are seen as 'co-experts' and have recently developed and validated an assessment tool through which carers

Primary Health Care Research \& Development 2008; 9: 14-24 
and practitioners can work together to agree the type of goals and outcomes that carers see as important and the support needed to achieve these (Hanson et al., 2006). The White Paper 'Our health, our care, our say' (Department of Health, 2006) reflects these concerns in proposing specific initiatives intended to support family carers such as a national helpline and an expert carer programme to provide support and training for carers. However, an evaluation of the implementation of these recommendations suggests little evidence, to date, of a new deal for carers emerging (Opinion Leader Research, 2007).

Encouraging self-care reflected not only a desire to give patients control over their condition and promote independence, but also the need to contain costs. In this regard, promoting independence may lead to carers performing procedures that have traditionally been regarded as the province of nurses (Kirk and Glendinning, 1998). Whereas nurses vary in the extent to which they are prepared to delegate tasks to carers (Pickard et al., 2003), carers are increasingly undertaking highly complex nursing tasks on behalf of professionals although they have little influence over the decision-making process (Pickard and Glendinning, 2002; Pickard et al., 2003). Although the nurses in the current study emphasized partnership working with family carers there is an inherent tension in the notion of partnership in which carers are perceived as valued co-workers and exploitation of carers to the nurses' advantage (McClure, 1995). Family carers as participants in health care generally have little choice other than to act as a resource filling in where service provision is lacking (Twigg and Atkin, 1994; Ross and Mackenzie, 1996).

The findings from the current study suggest that district nurses appear to work on the assumption that either by choice or by default, family members will take on care-giving responsibilities. The nurses' role is to support carers to continue care-giving, and whereas they may assist carers relinquish the care-giving role, this is generally in response to the carers' inability to continue, rather than an active choice on the part of carers. This stance is hardly surprising given that current policy is based on implicit assumptions and expectations regarding the nature of obligations between family members and the recipient of care

Primary Health Care Research \& Development 2008; 9: 14-24
(Pickard and Glendinning, 2002), an emphasis on self-care and pressure on resources. Yet it highlights the inherent tension in policy directives, which also call for increased consumer choice, which arguably should include carer as well as patient choice. As Arksey and Glendinning (2007) point out, the exercise of choice by carers is highly problematic if it involves relinquishing some unpaid care-giving activities.

\section{Conclusion}

In contrast to research that suggests that district nurses provide limited support for family carers, this study has identified the characteristics of nursing intervention intended to assist family carers fulfil their role. Such support is conceptualized within a professional ideology in which the needs of patients take precedence over those of carers and which is driven by a concern to promote patients' independence from nursing care. Moreover, carer support is conducted in a largely passive manner with limited engagement of family carers in making informed choices about their role as caregiver. It is also apparent that carer support is conditional on a number of factors, which may serve to limit the potential for family carers to benefit from district nursing intervention. These contextual issues all create very real tensions and competing pressures for district nurses in providing support for family carers.

As policy trends to increase the scope of homebased nursing continue, district nurses face new challenges in terms of their role in supporting family carers. Taking an active rather than passive stance and adopting a family rather than patientfocused approach could enable the needs of family carers to be identified more effectively. However, such developments need to be considered within the broader health care and social care policy context and alongside the responsibilities of other health care and social care professionals to support family carers. The interagency situation is complex and takes place within an environment where financial resources are stretched. Nevertheless, district nurses need to build upon their existing practice in supporting family carers to develop new forms of carer support which draw on carers' perceptions of how they want to be supported. 


\section{References}

Adler, P.A. and Adler, P. 1998: Observational techniques. In Denzin, N.K. and Lincoln, Y.S., editors, Collecting and Interpreting qualitative materials. Thousand Oaks: Sage, 79-109.

Arksey, H. and Glendinning, C. 2007: Choice in the context of informal care-giving. Health and Social Care in the Community 15, 165-75.

Arksey, H. and Hirst, M. 2005: Unpaid carers' access to and use of primary care services. Primary Health Care Research and Development 6, 101-06.

Audit Commission. 2004: Support for carers of older people: Independence and well-being 5. London: Audit Commission.

Brereton, L. and Nolan, M. 2002: 'Seeking': a key activity for new family carers of stroke survivors. Journal of Clinical Nursing 11, 22-31.

Cameron, E., Badger, F., Evers, H. and Atkin, K. 1988: Black old women, disability and health carers. Birmingham: Health Services Research Centre, University of Birmingham.

Cozens, A. 2002: Findings from the ADSS Survey on the implementation of the Carers and Disabled Children Act 2000. Association of Directors of Social Services.

Department of Health. 1999: Caring about carers: a national strategy for carers. London: Department of Health.

Department of Health. 2006: Our health, our care, our say: a new direction for community services. London: Department of Health.

Gerrish, K. 2000: Individualised care: its conceptualisation and practice within a multi-ethnic society. Journal of Advanced Nursing 32, 91-99.

Gerrish, K., Chau, R., Sobowale, A. and Birks, E. 2004: Bridging the language barrier: the use of interpreters in primary care nursing. Health and Social Care in the Community 12, 407-13.

Glendinning, C. 2003: Support for carers of older people: some intranational and national comparisons. London: Audit Commission.

Hammersley, M. and Atkinson, P. 1995: Ethnography: principles and practice, second edition. London: Routledge.

Hanson, E., Nolan, J., Magnusson, L., Sennemark, E., Johansson, L. and Nolan, M. 2006: COAT: the Carers Outcome Agreement Tool: a new approach to working with family carers. Sheffield: University of Sheffield.

Henwood, M. 1998: Ignored or invisible? Carers experience of the NHS. London: National Carers Association.

Katamba, S. and Bhakta, P. 1998. Experiences and needs of carers from South Asian communities. In Working Paper No 2. Leicester: Nuffield Community Care Studies Unit.

Katbamna, S., Ahmad, W., Bhakta, P., Baker, R. and Parker, G. 2004: Do they look after their own? Informal support for South Asian carers. Health and Social Care in the Community 12, 389-406.
Keeley, B. and Clarke, M. 2003a: Carers speak out project: report on findings and recommendations. London: The Princess Royal Trust for Carers.

Keeley, B. and Clarke, M. 2003b: Primary carers: identifying and providing support to carers in primary care. London: The Princess Royal Trust for Carers.

Kirk, S. and Glendinning, C. 1998: Trends in community care and patient participation: implications for the roles of informal carers and community nurses in the United Kingdom. Journal of Advanced Nursing 28, 370-81.

Luker, K., Wilson, K., Pateman, B. and Beaver, K. 2003: The role of district nursing: perspectives of cancer patients and their carers before and after hospital discharge. European Journal of Cancer Care 12, 308-16.

Manthorpe, J., Iliffe, S. and Eden, A. 2003: Testing Twigg and Atkin's typology of caring: a study of primary care professionals' perceptions of dementia care using a modified focus group method. Health and Social Care in the Community 11, 477-85.

McClure, L. 1995: Community nurses and carers: what price support and partnership? In Cain, P., Hyde, V. and Howkins, E., editors, Community nursing: dimensions and dilemmas. London: Arnold, pp. 42-65.

McGarry, J. and Arthur, A. 2001: Informal caring in later life: a qualitative study of the experiences of older carers. Journal of Advanced Nursing 33, 182-89.

Merrell, J., Kinsella, F., Murphy, F., Philpin, S. and Ali, A. 2005: Support needs of carers of dependent adults from a Bangladeshi community. Journal of Advanced Nursing 51, 545-48.

Nolan, M. and Grant, G. 1989: Addressing the needs of informal carers: a neglected area of nursing. Journal of Advanced Nursing 14, 950-61.

Nolan, M., Grant, G. and Keady, J. 1996: Understanding family care. Buckingham: Open University Press.

Nolan, M., Lundh, U., Grant, G. and Keady, J. 2003: Partnerships in Family Care: understanding the caregiving career. Maidenhead: Open University Press.

Ong, B.N. 1990: Researching needs in district nursing. Journal of Advanced Nursing 16, 638-47.

Opinion Leader Research. 2007: Our health, our care, our say one year on: research report. London: Department of Health.

Parker, G. and Lawton, D. 1994: Different types of care, different types of carer: evidence from the general household survey. London: HMSO.

Pickard, S. and Glendinning, C. 2002: Comparing and contrasting the role of family carers and nurses in the domestic health care of frail older people. Health and Social Care in the Community 10, 144-50.

Pickard, S., Shaw, S. and Glendinning, C. 2000: Health care professionals's support for older carers. Ageing and Society 20, 725-44.

Pickard, S., Jacobs, S. and Kirk, S. 2003: Challenging professional roles: lay carers' involvement in health care in the community. Social Policy and Administration 37, 82-96.

Primary Health Care Research \& Development 2008; 9: 14-24 


\section{Kate Gerrish}

Ross, F. and Mackenzie, A. 1996: Nursing in primary health care: policy into practice. London: Routledge.

Schatzman, L. 1991: Dimensional analysis: notes on an alternative approach to the grounding of theory in qualitative research. In Maines, D.R., editor, Social organisation and social process. New York: Aldine, 303-14.

Simon, C. and Kendrick, T. 2001: Informal carers - the role of general practitioners and district nurses. British Journal of General Practice 51, 655-57.

Twigg, J. and Atkin, K. 1994: Carers perceived: policy and practice in informal care. Buckingham: Open University Press.
Twigg, J., Atkin, K. and Perring, C. 1990: Carers and Services: A Review of Research. London: HMSO.

Walker, E. and Dewar, B. 2001: How do we facilitate carers' involvement in decision making? Journal of Advanced Nursing 34, 329-37.

Ward-Griffin, C. and McKeever, P. 2000: Relationships between nurses and family caregivers: partners in care? Advances in Nursing Sciences 22, 89-103.

Wiles, J. 2003: Informal caregivers' experiences of formal support in a changing context. Health and Social Care in the Community 11, 189-207. 